\title{
As fases da Lua, os eclipses e as relações espaciais: um estudo piagetiano
}

The Moon phases, eclipses and spatial relations: a piagetian study

Amanda de Mattos Pereira Mano ${ }^{1}$

Eliane Giachetto Saravali

\section{Resumo}

Apresentam-se os resultados de uma investigação que teve por objetivo identificar a solidariedade entre a compreensão dos fenômenos das fases lunares e dos Eclipses e a construção de relações espaciais, junto a escolares do ensino fundamental II. Foram participantes deste estudo 20 estudantes, matriculados no $8^{\circ}$ ano da rede pública de ensino de uma cidade do interior do estado de São Paulo, com idade entre 13 e 14 anos. Os instrumentos utilizados foram uma entrevista pautada no método clínico-crítico piagetiano, acerca da ocorrência das fases da Lua e dos Eclipses e uma prova operatória que investigou, por meio do problema da projeção das sombras, as relações espaciais. Os resultados das entrevistas revelaram que a maior parte dos participantes não compreende os fenômenos astronômicos investigados, e suas ideias não são pautadas em aspectos científicos, prevalecendo concepções muito centradas em sua própria perspectiva, sem coordená-las em um sistema espacial de relações. A aplicação da prova operatória revelou a prevalência de construções topológicas e euclidianas, com algumas construções iniciais do espaço projetivo. A análise estatística revelou relação positiva entre os dados dos dois instrumentos. São feitas reflexões sobre as implicações para o ensino de Ciências, em específico da Astronomia.

Palavras chave: Jean Piaget; construção do espaço; Astronomia.

\section{Abstract}

The results of an investigation that aimed to identify the solidarity between the understanding of the lunar phase's phenomena, Eclipses and the construction of spatial relationships, together with elementary school students are presented in this work. Twenty students enrolled in the 8th year of the public school system in an inner city of the São Paulo state, aged between 13 and 14 years, participated in this study. The instruments used were an interview based on the Piagetian clinical-critical method, about the occurrence of the Moon phases and Eclipses, and an operational test that investigated, through the shadow projection problem, the spatial relationships. The interviews answers revealed that most of the participants do not understand the investigated astronomical phenomena, and their ideas are not based on scientific aspects, prevailing conceptions that are very centered on their own perspective, without coordinating them in a spatial system of relationships. The application of the operative test revealed the prevalence of topological and Euclidean

\footnotetext{
${ }^{1}$ Universidade Federal de Mato Grosso do Sul | amanda.mano@ufms.br

${ }^{2}$ Universidade Estadual Paulista Júlio de Mesquita Filho | eliane.g.saravali@unesp.br
} 
constructions, with some initial constructions from the projective space. Statistical analysis revealed a positive relationship between the data from the two instruments. Reflections are made on the implications for the teaching of Science, specifically Astronomy.

Keywords: Jean Piaget; space construction; Astronomy.

\section{Introdução}

As reflexões apresentadas neste artigo são parte de uma pesquisa que teve o objetivo de verificar a compreensão que estudantes possuem a respeito das fases da Lua e dos Eclipses e a construção de relações espaciais.

A motivação em pesquisar a temática advém de nossa experiência enquanto professoras das disciplinas de Ciências e de Biologia e na formação de docentes da área, no ensino fundamental II, ensino médio e ensino superior. O ensino de ciências é sempre um desafio a professores que se encontram diante da necessidade de conciliar conteúdos, materiais teóricos, laboratórios, processos cognitivos, interesses e informações diversas que seus alunos possuem.

Dentre esses principais desafios, pesquisadores abordam o ensino ainda muito pautado na transmissão passiva de conhecimentos (BASSOLI, 2014); a formação de professores de Ciências e Biologia com base no bacharelado e pouco atrelada à identidade docente (BASTOS; CHAVES, 2018); a necessidade da utilização de materiais concretos que apoiem o pensamento dos estudantes (MANO; SARAVALI, 2019), entre outros.

Ao longo de nossa experiência, observávamos concepções muito curiosas, por parte dos alunos, em relação a diferentes fenômenos, indicando formas singulares de compreender e agir no mundo. Diante de tais concepções, por vezes, acompanhávamos que grande parte dos estudantes apresentava dificuldades de compreensão e, por conseguinte, de aprendizagem quando eram abordados conceitos, termos e/ou nomenclaturas científicas.

A concepção de Jean Piaget (1896-1980) a respeito do desenvolvimento e da aprendizagem é de natureza interacionista e construtivista, em que o conhecimento não é concebido como algo já pré-determinado, inerente ao nosso nascimento, tampouco determinado pela recepção e acúmulo de informações do ambiente. Asseverar a natureza construtivista do desenvolvimento implica a compreensão de que o conhecimento é construído num árduo processo que envolve múltiplas interações entre sujeitos e aquilo que será conhecido. Ainda, é fundamental compreender que o conhecimento possui uma gênese e constantes reorganizações mentais conferindo aos sujeitos conhecimentos cada vez mais elaborados (PIAGET, [1972], 1977).

Assim, são necessárias importantes interações que dependem do exterior (meio ambiente) e do interior (sujeito), as quais fundamentalmente devem agir em direções complementares e solidárias para a construção da inteligência (PIAGET, [1970], 2007). A interação entre sujeito e meio ambiente só pode acontecer por meio da ação. Entretanto, na perspectiva piagetiana, ao contrário do que o senso comum pode nos levar a inferir, a ação não se refere apenas ao ato manipulativo, mas também a uma ação que ocorre no plano do pensamento, de maneira que "[...] todo conhecimento está ligado a uma ação e que conhecer um objeto ou acontecimento é utilizá-los, assimilando-os a esquemas de ação." (PIAGET, [1967], 2003, p. 15). Nota-se que o conhecimento procede da ação, mas é interpretado pelo emprego de esquemas de ação, de sorte que temos a possibilidade de 
nos desprendermos do ato manipulativo, propriamente dito, para o plano de organizações e combinações do pensamento. Nesse sentido, conhecer é transformar, relacionar, coordenar.

O desenvolvimento da inteligência, portanto, têm na interação seu leque de possibilidades. Todavia, é importante refletir acerca da qualidade dessas interações, uma vez que não se trata apenas de interagir em maior número, mas de ser provocado cognitivamente ao ponto de novas construções serem solicitadas e desencadeadas.

Nesse domínio, Piaget ([1975], 1976) explica que existem dois processos fundamentais, a assimilação e a acomodação, invariantes funcionais complementares, que conferem organização e adaptação do sujeito no/ao mundo.

A assimilação permite ao sujeito atribuir um sentido àquilo que se busca conhecer, mediante a inserção da informação no sistema motor, cognitivo etc., de tal forma que condições individuais permitem ou não possibilidades de incorporação do dado externo, possibilidades estas subordinadas aos esquemas e estruturas mentais do sujeito. De maneira complementar, a acomodação provoca modificações e diferenciações nestes esquemas ou estruturas, devido às resistências em se assimilar da mesma forma que ocorria em outras situações. Daí a necessidade de se modificar ou completar o esquema.

Piaget ([1975], 1976, p. 14) salienta que "[...] todo esquema de assimilação é obrigado a se acomodar aos elementos que assimila, isto é, a se modificar em função de suas particularidades [...]". De tal afirmação retiramos que assimilação e acomodação são processos imbricados e que é necessário um equilíbrio entre eles. Quando o equilíbrio (ainda que momentâneo) se estabelece, podemos sustentar que ocorreu uma adaptação constância entre assimilação e acomodação.

Considerar esse funcionamento em atividades envolvendo o ensino nos alerta para algumas questões importantes, ou seja, os alunos estarão constantemente realizando processos de assimilação e acomodação, de tal forma a dar sentido aos conteúdos, aulas e situações escolares, ao mesmo tempo em que se transformam, na busca por equilíbrios melhores. Assim, é papel do professor a criação de inúmeras oportunidades de desestabilização desse sistema, ativando os componentes necessários ao equilíbrio. Segundo Zaia, "para que uma situação seja estimulante e desafiadora deve estar um pouco acima das possibilidades atuais da criança, mas próxima o suficiente para ser compreensível e solucionável. (2015, p. 149)."

Muitos pesquisadores tratam de questões envolvendo o ensino de ciências na perspectiva piagetiana. Nardi e Carvalho (1996), em estudo pioneiro na área, abordaram a evolução das noções de forma, espaço e força gravitacional do planeta Terra em estudantes da educação básica; Eicheler, Parrat-Dayan e Fagundes (2008) investigaram sobre as explicações causais dos estados de mudança da matéria, por meio do problema da sublimação do iodo; Barbosa e Souza (2018) apresentaram uma intervenção pedagógica, pautada em princípios da teoria piagetiana, a respeito do conteúdo - insetos.

Em um trabalho de revisão bibliográfica nos principais periódicos de nosso país, Moraes (2017) constatou que a teoria de Piaget, como fundamento para o ensino de Ciências, tem sido utilizada, principalmente, para destacar a importância de estratégias de ensino, isto é, experimentos, atividades, metodologias com crianças e adolescentes que encaminhem um aprendizado mais significativo.

Conteúdos relacionados à Astronomia mostram-se como de grande dificuldade para aqueles que precisam ensinar Ciências (MANO, 2017) e alguns autores exploraram tais 
dificuldades na perspectiva piagetiana, tais como Leite (2006) que desenvolveu uma formação para professores com enfoque na espacialidade e Bartelmebs e Moraes (2012) sobre as contribuições do construtivismo para o Ensino de Conteúdos de Astronomia nos anos iniciais.

Temas importantes relacionados à Astronomia e que costumam despertar o interesse e a curiosidade dos estudantes são os relacionados às fases da Lua e aos Eclipses. Alguns autores identificaram a dificuldade dos alunos em compreenderem esses fenômenos por meio da perspectiva científica (TRUNDLE; ATWOOD; CHRISTOPHER, 2002; IACHEL; LANGHI; SCALVI, 2008; MACHADO; SANTOS, 2011; ELIAS; ARAÚJO; AMARAL, 2011; DARROZ et al., 2014; PELLENZ, 2015). Nestes estudos, fica claro a falta de aproximação das ideias que os sujeitos constroem com elementos mais próximos aos achados científicos.

Lago (2013) buscou sistematizar alguns argumentos que podem justificar a não compreensão do fenômeno das fases da Lua, por parte dos alunos da educação básica, e que podemos estender à dificuldade de outros grupos. Alguns deles são: elevada abstração; falta de percepção espacial e de raciocínio tridimensional; crenças iniciais persistentes e falta de conceitos.

Quanto à elevada abstração, sugere-se que a Lua e seus eventos, embora sejam observáveis, são objetos distantes de nossa realidade física, posto que não se apresentam em uma realidade "palpável", exceto com auxílio de modelos. Soma-se a isso uma possível dificuldade na construção da percepção espacial e do pensamento tridimensional, necessário para compreender, por exemplo, o reflexo da luz do Sol na Lua e o modo como o observador na Terra irá ver sua iluminação.

Por sua vez, a forte presença de concepções iniciais calcadas no senso comum, pode ser a causa da incompreensão de argumentos científicos. Nesse sentido, a existência de concepções nas quais se acredita que a Lua tem luz própria ou ainda que ela está no céu somente à noite, podem ser obstáculos para o entendimento de outras possibilidades.

Quanto à falta de conceitos, discute-se a importância sobre informações que são disponibilizadas aos alunos, limitadas à mera transmissão. É preciso, por exemplo, informálos ou apresentá-los a respeito do nome das fases da Lua, dos hemisférios, a duração das fases, entre outros termos importantes e necessários para a elaboração de conhecimentos científicos acerca da realidade dos astros. Entretanto, essas informações por si só são insuficientes para uma compreensão mais elaborada que consiga estabelecer relações, reorganizar transmissões e, portanto, construir conhecimentos.

Em função da necessidade de coordenação de muitas perspectivas para a compreensão de conteúdos do mundo astronômico, não nos causa estranheza que explicações alternativas às científicas habitem o pensamento das pessoas.

Gonçalves e Bretones (2020) destacam, em recente investigação sobre o panorama de pesquisas a respeito das fases da Lua no Brasil, serem poucos os estudos que se dedicam aos processos de pensamento dos alunos. Portanto, na busca de compreensão sobre essas questões encontramos na epistemologia e psicologia genéticas piagetianas importante referencial.

Ademais, a partir da teoria piagetiana, acreditamos que outras variáveis estariam ligadas à possibilidade de compreensão de fenômenos e dos conteúdos da Astronomia, uma delas seria a construção da noção de espaço, envolvendo as relações topológicas, euclidianas e projetivas. Conceber o universo, com suas particularidades e leis, consiste, na perspectiva piagetiana, em uma construção de categorias do real (PIAGET, [1937], 1975). 
Nessa construção, desenvolvem-se as noções de objeto, de tempo, de causalidade e de espaço.

Consideremos, então, nosso objeto - o fenômeno das fases da Lua. No que tange ao objeto permanente, para compreensão das fases, é necessário acreditar que se trata sempre da mesma Lua, e não de outras que aparecem e somem, semanalmente. Quanto ao tempo, observa-se a duração dos movimentos de rotação desse astro, ao redor da Terra, e destes em relação ao Sol. No que se refere à causalidade, acompanha-se a justificação do fenômeno por si só, face aos movimentos de rotação, ocasionando distintas posições da Lua em relação ao Sol e, por conseguinte, diferentes formas de iluminação lunar, vistas aqui da Terra. Já para as construções espaciais, observa-se a necessidade de compreensão de que todos os efetivos deslocamentos necessários ao fenômeno acontecem em um espaço e em espaços simultâneos. Em especial, sobre esta última categoria do real, na busca em realizar aproximações teóricas entre o mundo astronômico e a teoria piagetiana, nos dispusemos a pensar que o entendimento desses fenômenos, em realidade, constitui uma coordenação de perspectivas inerentes a uma construção mais organizada das relações espaciais.

Piaget e Inhelder ([1948], 1993) sistematizaram a evolução da representação do espaço no decorrer das relações de ordem topológica, euclidiana e projetiva.

Nas relações espaciais de ordem topológica, encontramos a compreensão dos fechamentos e contornos; isso quer dizer que a criança pode identificar a forma dos objetos, mas não, ainda, as formas geométricas, as quais necessitam de outras relações espaciais para serem entendidas, em sua totalidade.

Assim, as relações topológicas são descritas como sendo as mais elementares, tanto em sua ordem de construção quanto em sua natureza. Desse modo, já no bebê, podemos encontrar o início dessas relações, nas quais a organização do espaço confina cada objeto em si mesmo, visto que os elementos que compõem a realidade percebida não fazem referência à existência de um sistema de relações espaciais que, mais tarde, serão essenciais para uma compreensão mais elaborada do espaço.

Nesse particular, o progresso da motricidade e da percepção é o responsável por alicerçar os avanços no campo do espaço, de sorte que, por meio desses mecanismos, é possível a organização das primeiras relações espaciais, tais como vizinhança, separação, ordem, circunscrição (ou envoltório) e continuidade.

A relação mais elementar que a percepção pode proporcionar é a de vizinhança, isto é, a proximidade dos objetos que estão no mesmo campo. Outra relação espacial igualmente elementar e ligada à percepção da vizinhança é a de separação. À medida que elementos vizinhos e separados se organizam, faz-se necessária a intervenção da relação espacial de ordem. Com tal sucessão espacial, relaciona-se a noção de circunscrição, ou seja, os limites do objeto dos quais também se desdobram, na continuidade de linhas e superfícies.

Todas essas relações se desenvolvem ao longo do estádio sensório-motor (0 a 24 meses, aproximadamente). Logo, ao longo desse primeiro estádio de desenvolvimento, temos a construção do espaço de caráter perceptivo ou prático. Nesse sentido, se, em seus primeiros meses de vida, a criança não é capaz de distinguir os limites de seu corpo com o mundo, pouco a pouco eles vão sendo diferenciados e confinados em um sistema de relações, por meio da descentração do sujeito em relação aos objetos.

Vale ressaltar que as relações espaciais construídas até então são de caráter topológico e, mesmo com todas as conquistas descritas, é preciso que a criança avance, 
pois se trata, ainda, de uma perspectiva espacial limitada. Piaget e Inhelder ([1948], 1993) relatam que as crianças que usam as relações espaciais topológicas reconhecem facilmente objetos conhecidos, tais como uma bola, um pente, uma chave, entre outros. Porém, quando solicitados a reconhecer figuras geométricas, como um triângulo ou um quadrado, não conseguem fazê-lo, pois, para tais relações, é preciso a intervenção de relações espaciais euclidianas.

Ademais, é importante considerar que a construção das relações espaciais no campo perceptivo do sensório-motor será, mais tarde, reorganizada no plano da representação do estádio pré-operatório, de tal forma que o desafio ao sujeito será representar o espaço.

A passagem das relações espaciais topológicas às relações espaciais euclidianas só pode acontecer quando assegurada pelas representações. Com efeito, as crianças pouco a pouco vão abstraindo as propriedades de retas, de ângulos e de circunferência e, desse modo, passam a organizar tais propriedades mentalmente, em um sistema de relações que não estão confinadas no objeto. Zaia (2015) explica que a principal diferença entre as relações topológicas e as projetivas e euclidianas refere-se ao fato de que nas duas últimas são considerados sistemas que situam objetos e suas configurações - projeções, perspectivas e coordenadas.

Quando os objetos passam a não mais ser considerados como confinados em si mesmos e começam a ser analisados sob diferentes pontos de vista, sendo o do sujeito apenas um entre os possíveis, estamos em face das relações projetivas que "supõem uma coordenação entre objetos espaciais distintos, em oposição à análise intrínseca das relações topológicas próprias de cada objeto considerado em si mesmo." (PIAGET; INHELDER, [1948], 1993, p. 168).

É preciso entender que a construção da relação espacial do tipo projetiva favorece a criação de possibilidades que conferem ao sujeito novas formas de pensar as relações de perspectiva. Cremos que essas possibilidades devem estar presentes para entender os fenômenos astronômicos ligados à temática que destacamos, ou seja, as fases da Lua e os Eclipses.

Os estudos piagetianos mostram que não é o fato de os sujeitos observarem o fenômeno ou uma determinada situação que garante a compreensão e a construção de uma relação espacial projetiva, mas apenas quando da diferenciação e coordenação de perspectivas, a qual amplia a construção espacial, uma vez que, sem estas, é impossível compreender as relações entre os objetos. Assim, relações horizontais, verticais, em cima, em baixo, em frente e atrás são diferenciadas, todavia, ao mesmo tempo que se integram na constituição do espaço.

Quando pensamos nas questões que tangem a Astronomia básica, não conseguimos desvinculá-las de tais processos de descentração e de coordenação de perspectivas, fundamentais para a compreensão do espaço. Nesse sentido, acreditamos que, dificilmente, um aluno com dificuldades nesses processos conseguirá compreender a Astronomia, em sua totalidade, isto é, considerando e coordenando todos os aspectos envolvidos em uma compreensão mais ampla.

Especificamente, em relação às fases da Lua e os Eclipses, muitas são as aproximações entre a construção do espaço e o entendimento científico deste conteúdo. Por exemplo, para compreender essas temáticas, é necessário ter constituída visão heliocêntrica e, para isso, é preciso descentrar perspectivas, já que temos que nos abstrair do aparente 
movimento diário do Sol em volta da Terra, afinal, a percepção nos convence de que ele "nasce" de um lado e se "põe de outro".

Da mesma forma, para compreender que a Lua possui um movimento em torno da Terra e que, ao longo dessa trajetória, assume diferentes posições nas quais reflete a luz solar, é necessário, mais uma vez, lançar mão de um pensamento descentrado e com coordenação constante de perspectivas.

Diante destas questões, passaremos a apresentar os resultados de investigação que objetivou identificar a solidariedade existente entre a construção de relações espaciais e a compreensão dos fenômenos das fases lunares e dos Eclipses, junto a escolares do ensino fundamental II.

\section{Metodologia}

A pesquisa ${ }^{3}$ corresponde a um estudo de caso com abordagem mista, pois utilizou as contribuições das esferas quantitativa e qualitativa (CRESWELL, 2010). Foram participantes 20 estudantes, com idade entre 13 e 14 anos, de ambos os sexos, regularmente matriculados numa turma de $8^{\circ}$ ano do Ensino Fundamental II da rede estadual, no interior do estado de São Paulo.

Para a coleta de dados foram empregados dois instrumentos, sendo o primeiro uma entrevista clínico-crítica (PIAGET, [1926], 2005) acerca dos motivos para a ocorrência das fases da Lua e dos Eclipses. A esse respeito, primeiramente, os participantes foram questionados se a Lua estaria sempre do mesmo jeito no céu, de quais formas já puderam visualiza-la e porque ela assumiria diferentes formas. Em acréscimo, perguntou-se sobre a ocorrência dos Eclipses utilizando um vídeo adaptado ${ }^{4}$ que mostrava um Eclipse lunar, em modo acelerado e, em seguida, foram feitas as questões: o que é isso que está acontecendo? Por que isso acontece? Caso o estudante não falasse algo relacionado aos Eclipses, perguntava-se: você conhece a palavra Eclipse? O que é um Eclipse?

Em sequência à entrevista, o segundo instrumento utilizado foi a aplicação da prova operatória "A projeção de sombras" (PIAGET; INHELDER, [1948], 1993). Esta situação experimental consiste na apresentação de diferentes objetos ao participante, na posição vertical, horizontal e oblíqua, questionando-o sobre como seria a sombra dos mesmos quando colocados entre uma fonte luminosa e a parede. Foram utilizados os seguintes objetos: 1) um cone de papel com a base fechada, 2) um cone de papel com um furo na ponta e de base aberta, 3) dois cones de papel, unidos por suas bases, 4) um círculo de papel cartão, 5) um retângulo de papelão e 6) um lápis com ponta. O sujeito, inicialmente, antecipava como seria a sombra, desenhando-a e explicando suas hipóteses. Em seguida, projetava-se a sombra e o participante comparava sua previsão com o que estava vendo projetado na parede.

As respostas dos sujeitos nos dois instrumentos foram submetidas à análise qualitativa em que se priorizou os conteúdos e a forma como os problemas propostos eram resolvidos. Procedeu-se, também, a análise quantitativa por meio da estatística descritiva, por meio do software Statistica ${ }^{\circledR}$ versão 10 (StatSoft, Inc), na aplicação do teste estatístico

\footnotetext{
${ }^{3}$ Financiada pela CAPES.

${ }^{4}$ Disponível em: https://www.youtube.com/watch?v=OCJzO38jn. Acesso em 31 mai. 2021.
} 
não-paramétrico de Wilcoxon para averiguar a presença de relações e correlações entre as variáveis investigadas. Em busca de uma maior confiabilidade nos resultados, as provas operatórias aplicadas passaram pelo critério da análise de juízes (FAGUNDES, 1981). Por isso, um percentual de $10 \%$ do total das provas operatórias foi repassado ao crivo de dois experientes pesquisadores da área. Os resultados encontrados pelos juízes compuseram um índice de concordância de 76,38\%. Como o ideal mínimo de confiabilidade é de 70\%, podemos afirmar que nossos percentuais mostram a confiabilidade das análises.

A amostra foi composta por conveniência a medida em que a equipe gestora da escola e os docentes receberam, autorizaram a coleta de dados e incentivaram a realização da pesquisa. Os alunos foram entrevistados individualmente em uma sala reservada pela instituição; gravou-se a entrevista e a aplicação da prova por áudio e vídeo e, posteriormente, foram transcritas para as análises.

Todos os procedimentos, bem como autorizações e termos de consentimento e assentimento foram submetidos e aprovados pelo Comitê de Ética em pesquisa local, mediante o cadastro na Plataforma Brasil.

\section{Resultados e discussões}

Em relação aos motivos sobre os quais ocorrem as fases lunares, as respostas puderam ser enquadradas em cinco categorias, conforme acompanha-se no Gráfico 1, a seguir.

Gráfico 1 - Categorias de respostas para explicar o fenômeno das Fases da Lua

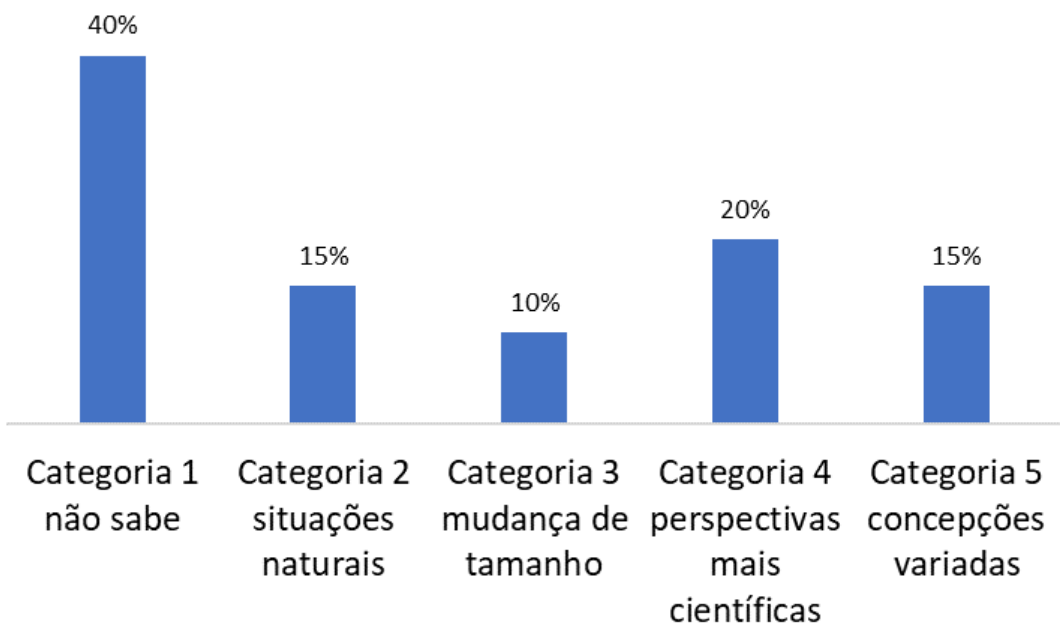

Fonte: Dados da pesquisa.

Com 40\% dos participantes, na primeira categoria estão as respostas dos estudantes que afirmaram não saber o motivo para a ocorrência das fases da Lua. Atenta-se para o fato de que não são estudantes que desconhecem o fenômeno, pois anteriormente ao questionamento sobre o motivo das fases, todos responderam já ter visto alguma fase da Lua, tais como a Cheia ou a Minguante. No entanto, nossos participantes não conseguiram abordar nenhum fator para explicá-lo.

Acreditamos que o não fornecimento de explicações remete ao que anteriormente citamos sobre o fato de que não basta observar o fenômeno para compreendê-lo. É preciso receber e relacionar informações, fazer inferências, criar hipóteses. Entretanto, para que isso 
aconteça, os alunos precisam ser levados à reflexão, isto é, desafiados a conhecer e interpretar o fenômeno.

A segunda categoria, com 15\% das respostas, é representada pelas concepções que revelam a ideia de que as fases da Lua são situações naturais, as quais podem acontecer, porque o tempo vai passando e, assim, parte da Lua vai sumindo e aparecendo, conforme um participante "ela muda de forma conforme vai passando os dias." Desse modo, nota-se que estas ideias evidenciam que esses estudantes acreditam no fenômeno como fruto da regularidade do tempo, não atribuindo sua ocorrência a nenhum outro aspecto.

A terceira categoria, com 10\% das respostas, revela a compreensão de que durante as fases da Lua o astro pode diminuir e/ou aumentar de tamanho, como: "A crescente é pequenininha e a cheia maior". Nota-se que estamos diante de afirmações que demonstram o desconhecimento dos alunos quanto às características lunares, tais como composição e tamanho. Essa categoria nos despertou atenção, haja vista que nossos investigados são estudantes já com 13 ou 14 anos e que, em tese, teriam possibilidades para se desprender das aparências e realizar abstrações mais elaboradas, até mesmo no plano hipotéticodedutivo.

Na quarta categoria, com 20\% das respostas, estão as explicações que podem ser consideradas como mais próximas à perspectiva científica, porém, ainda superficiais. Um dos participantes, por exemplo, ao ser questionado acerca da ocorrência das fases nos disse: "[...] é que a Lua vai aparecendo por partes, vamos supor que o Sol bate e reflete nela, aí aparece". Observa-se nesta explicação que, embora alguns elementos científicos estejam presentes, tais como, a Lua refletir os raios solares, ainda se retrata uma forma muito superficial de interpretação, pois não há demonstração de uma compreensão clara e segura do fenômeno.

Em uma última categoria, com 15\% das respostas, estão presentes distintas e únicas concepções, as quais optamos por uni-las pois, isoladas, não seriam estatisticamente significativas. São elas, a ideia de que Planetas cobrem a Lua, afirmado no seguinte excerto: "e os planetas giram em volta da Lua e eles passam pela Lua e eu acho que cobre", bem como a concepção de que a sombra da Terra na Lua é responsável pelas fases lunares.

Portanto, em relação às fases da Lua, observamos em $40 \%$ das respostas que os estudantes não sabem explicar as causas. Os demais, quando possuem uma explicação, observada na soma das categorias 2, 3 e 5, também com percentual de 40\%, apresentam concepções singulares revelando a pouca utilização de explicações mais próximas aos conceitos científicos.

No que tange a investigação sobre a compreensão acerca dos Eclipses, as respostas também puderam ser enquadradas em cinco categorias, conforme observa-se no Gráfico 2, em sequência.

Diferentemente do fenômeno das fases da Lua, a primeira categoria relacionada às explicações para a ocorrência dos Eclipses revela um percentual de 10\% de sujeitos que afirmaram desconhecê-lo. É importante frisar que, após assistir ao vídeo, os alunos eram questionados sobre o que haviam visto e, caso eles não mencionassem o fenômeno em questão, a pesquisadora perguntava se eles já tinham, ao menos, ouvido a palavra Eclipse. No entanto, ainda assim, permaneceram respostas que mostraram total desconhecimento deste fenômeno. 
Gráfico 2 - Categorias de respostas para explicar o fenômeno dos Eclipses

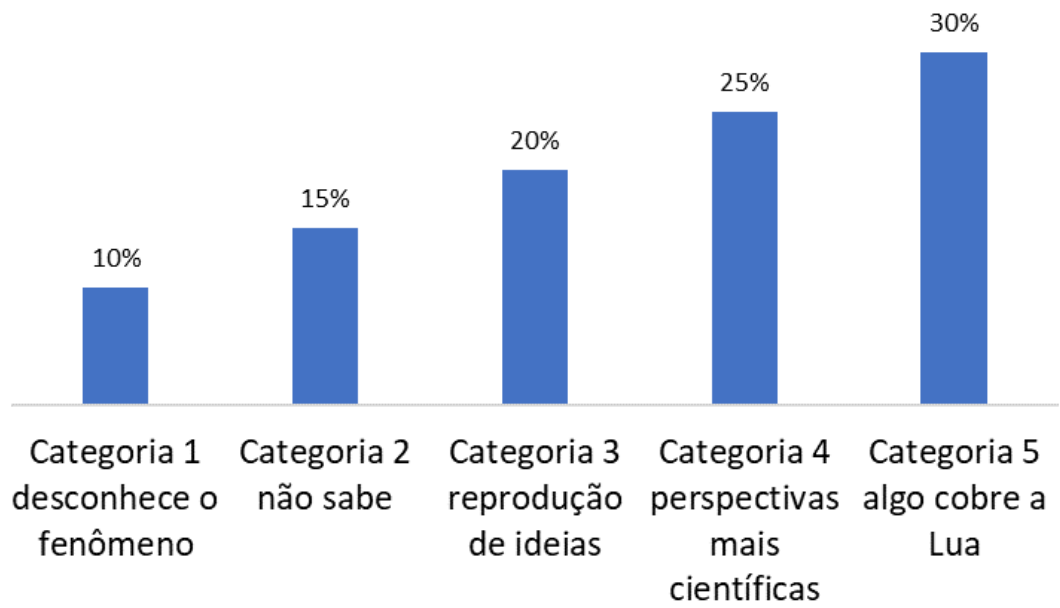

Fonte: Dados da pesquisa.

Na segunda categoria, 15\%, estão os estudantes que relataram não saber explicar o fenômeno. Com efeito, esta é uma categoria distinta da primeira pois, aqui, os participantes declararam conhecer o fenômeno dos Eclipses, porém, não sabem explicar os motivos de sua ocorrência.

Na terceira categoria, com 20\%, enquadram-se as falas que trazem alguma explicação para o fenômeno dos Eclipses. São respostas que apenas reproduzem ideias veiculadas no senso comum, tais como "a Lua passa pelo Sol" ou então "A Lua entrou na frente do Sol" e, embora sejam ideias com afirmações próximas à perspectiva científica, quando questionados sobre como, de fato, essas situações acontecem, os alunos não conseguem dar mais detalhes ou, quando o fazem, são explicações vagas e imprecisas.

A quarta categoria, com 25\% das respostas, revela as interpretações que mais se aproximam das explicações científicas. Nota-se a presença de elementos científicos, como o movimento da Terra e sua necessidade de alinhamento com o Sol, para a ocorrência dos Eclipses. Entretanto, quando solicitado a explicar melhor o fenômeno, falta ao estudante objetividade científica, tornando a resposta confusa.

Por fim, tem-se uma última categoria, sendo 30\% do percentual de respostas, na qual há a ideia de que algo precisa "cobrir a Lua" e, para isso, recorre-se às nuvens ou outros planetas cobrindo o astro. Ainda que nesta categoria o pensamento revele uma aproximação científica pela compreensão de que algo cobriria a Lua, isso não se relacionaria ao posicionamento da Terra entre o Sol e a Lua, tal qual em um Eclipse lunar, mas a fatores alheios a movimentação dos astros envolvidos neste fenômeno.

Acerca da explicação para a ocorrência dos Eclipses, as categorias 3 e 4 são aquelas que, de alguma maneira, trazem ideias que mais se aproximam da perspectiva científica. Somando o percentual de ambas, temos que $45 \%$ dos participantes trazem esses elementos às suas explicações quanto à ocorrência dos Eclipses, mesmo de maneira incompleta.

Todavia, o fato de termos um percentual de $30 \%$ de concepções alternativas, nas quais nuvens ou planetas cobrem a Lua, nos chama atenção, uma vez que esse resultado remete ao fato de que as explicações sobre o fenômeno se centram apenas em um único astro, isto é, na Lua, sem considerar as demais configurações e elementos que estão envolvidos na ocorrência do Eclipse. 
De maneira geral, os resultados obtidos com a entrevista corroboram achados que evidenciam a ausência da perspectiva científica e suas implicações nas concepções sobre o assunto (PUZZO, 2005; COSTA; GERMANO, 2011; DARROZ et al., 2013; LAGO; ORTEGA; MATOS, 2019).

Vejamos, a seguir, os dados obtidos a partir da prova operatória que tem por objetivo verificar como são construídas as representações espaciais da projeção das sombras, a nosso ver, imprescindíveis para a compreensão dos fenômenos das fases da Lua e dos Eclipses.

Para essa situação, é preciso conceber as relações entre o objeto a ser projetado e o sujeito, bem como a relação entre dois objetos (o projetado e a fonte luminosa). As resoluções para o problema das sombras dos objetos foram enquadradas em estádios (I, II, III e IV) e subestádios (A, B) conforme os protocolos de Piaget e Inhelder ([1948], 1993).

Em nossa pesquisa, nenhum participante apresentou conduta condizente ao primeiro estádio, que seria o mais elementar quanto às construções espaciais. Vejamos no Gráfico 3, a seguir, os subestádios encontrados na investigação.

Gráfico 3 - Subestádios da prova operatória "A projeção de sombras" encontrados na pesquisa

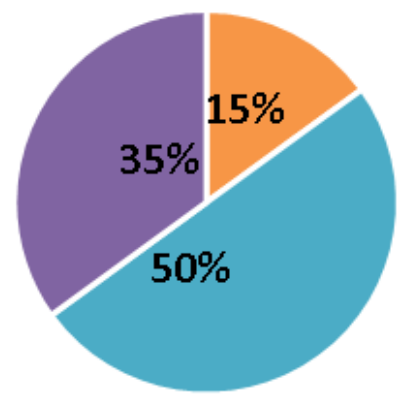

\section{- Subestádio IIA $\|$ Subestádio IIB $\|$ Subestádio IIIA}

Fonte: Dados da pesquisa.

Em relação ao subestádio IIA, encontramos 15\% dos participantes que embora tenham refletido sobre as sombras, fornecem explicações muito vagas que não constituem, por ora, um início de descentração. Isso ocorre porque a sombra antecipada remete-se à forma do objeto que the é apresentado, sem considerar, por exemplo, a fonte luminosa e as coordenações entre essa fonte, o objeto e o local de projeção (parede).

A descentração tem início no momento B deste segundo estádio, em nossa pesquisa representada por 50\% dos participantes. Aqui percebe-se que há uma dissociação do formato do objeto à formação da sombra, tanto nas posições horizontais, como nas verticais. Isso ocorre, sobretudo, no caso das figuras planas, nem sempre sendo expandido para as sombras dos cones, por exemplo. Vejamos os desenhos 1 e 2, a seguir, a título de ilustração: 
Desenho 1 - Subestádio IIB - figuras cônicas em diferentes posições

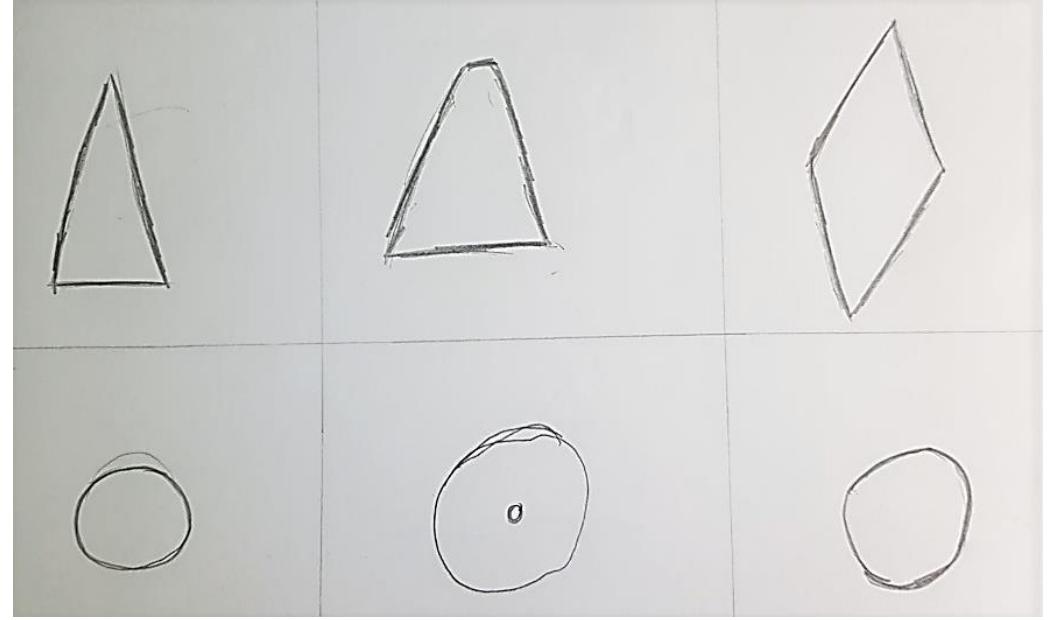

Fonte: Dados da pesquisa.

Desenho 2 - Subestádio II B - figuras planas e lápis em diferentes posições

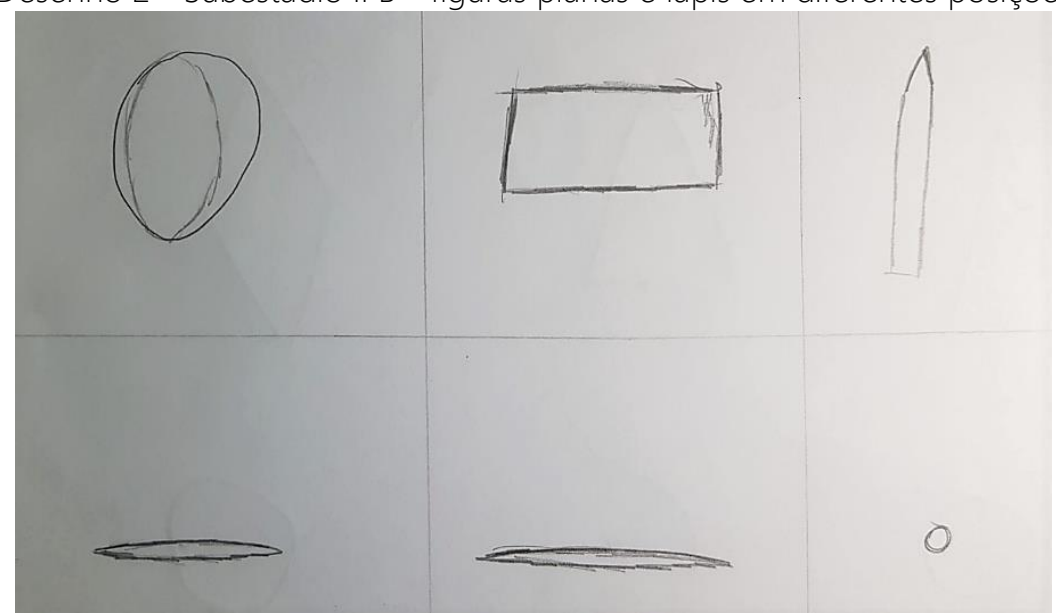

Fonte: Dados da pesquisa.

A partir dos Desenhos 1 e 2 apresentados nota-se que os sujeitos já compreendem que a sombra não está diretamente ligada ao objeto e, por isso, buscam representá-la considerando o percurso da luz face à peça apresentada, ou como nos disse um dos entrevistados: "a sombra depende de onde a luz não pega".

Todavia, os objetos colocam limitações ao pensamento que precisa se desprender do real e conceber relações de perspectiva entre as variáveis envolvidas na formação das sombras. Por isso, não existe exatidão quanto às relações frente-atrás e direita-esquerda. Nos dizeres de Piaget e Inhelder ([1948], 1993, p. 213) isso se dá "por confusão do eixo luzobjeto-anteparo com o ponto de vista do próprio sujeito, portanto a projeção com o ponto de vista próprio".

Destaca-se que a metade de nossos participantes apresentou essa forma de pensar. Ao relacionar esse pensamento com a compreensão acerca das fases da Lua e dos Eclipses, percebe-se a dificuldade em coordenar os elementos envolvidos na perspectiva científica, uma vez que a partir das entrevistas pode ser revelado que os sujeitos centram-se ora na Lua, ora na Terra sem, de fato, construir uma relação entre os elementos.

No estádio IIIA, obtém-se a completa diferenciação das formas das sombras e 35\% das respostas de nossos participantes puderam ser enquadradas aqui. Entretanto, observou-se 
que os sujeitos não compreendem a causa deste fenômeno, isto é, das sombras. em específico, para as formas cônicas. Ademais, não se prevê com regularidade a sombra projetada pelas posições oblíquas/ inclinadas, isto é, nas diferentes posições apresentadas.

Leite e Hosoume (2007) também encontraram participantes que recorrem à forma plana dos objetos astronômicos, por serem mais próximas da observação direta, uma vez que ao olharmos a Lua no céu, em imagens ou em vídeos não a vemos em três dimensões. Ainda, tem-se a expressão "face oculta da Lua" que pode encaminhar o imaginário a algo plano, pois esta denominação não é muito característica de uma esfera. Certamente, essas limitações do pensamento, impostas pelas características dos objetos e pela ausência de descentração, interferem na forma de compreender globalmente as fases da Lua e os Eclipses.

Em nossa pesquisa junto a escolares já adolescentes, não encontramos sujeitos que estivessem nos estádios IIIB e IV, os quais possibilitariam a coordenação entre os objetos, a fonte luminosa e a projeção das sombras, bem como a quantificação das sombras, ou seja, em todos os casos o participante é capaz de predizer a sombra com exatidão em todas as posições que o objeto estaria em relação à fonte luminosa e a parede.

Desse modo, cabe frisar que os participantes de nossa pesquisa, no geral, tiveram muitas dúvidas com relação ao problema físico de formação das sombras.

Em acréscimo aos nossos resultados qualitativos, apoiados pela estatística básica por meio do cálculo da frequência relativa das respostas, os dados também foram submetidos ao tratamento do teste não-paramétrico de Wilcoxon, que investiga a relação de dependência entre as variáveis, em nosso caso, a correlação entre categorias de explicações sobre a ocorrência das fases da Lua e Eclipses e a construção das relações espaciais investigadas.

Definimos a hipótese nula $\left(H_{0}\right)$, na qual explicitou-se que não haveria diferença entre as variáveis, ou melhor, as respostas da prova operatória e as categorias das entrevistas não estariam atreladas, já de acordo com a hipótese alternativa $\left(H_{1}\right)$ existiria correlação entre as variáveis pesquisadas.

Para existência de correlação estatisticamente significativa, a probabilidade de significância ( $p$ ) deve ser menor que 5\% (0,05), ou seja, rejeita-se a hipótese nula. Quando o valor de p for igual ou maior do que 5\% $(0,05)$, a correlação estatística encontrada é não significativa, assim, aceita-se a hipótese nula.

Após a aplicação do teste estatístico encontrou-se um p=0,000089 para as categorias de respostas sobre as Fases da Lua e $p=0,000293$ nas categorias relacionadas às explicações para os Eclipses, ambas em relação à prova operatória.

Dessa maneira, as relações entre as categorias de respostas da entrevista e os subestádios nas provas operatórias foram significativas estatisticamente, uma vez que observamos um número de $p<0,05$. Isso implica dizer que existe uma correlação positiva entre as respostas das entrevistas e os níveis da prova operatória.

Esse resultado nos permite afirmar que a construção de interpretações próximas à perspectiva científica, ainda que incompletas, está relacionada à construção de noções espaciais do tipo topológicas e euclidianas, caracterizadas pelo subnível IIB, adentrando às construções projetivas como visto em IIIA, subníveis estes mais encontrados nesta investigação. Assim, nossos resultados apontam para a existência de relações entre estes sistemas, cujas construções simultâneas reunidas podem gerar formação de novas 
totalidades, assim como estabeleceu Piaget ([1980], 1996). Tal aspecto traz implicações pedagógicas decorrentes que abordamos a seguir.

É preciso frisar que o contato com os conteúdos da Astronomia básica não era novidade para nossos participantes, visto que, de acordo com o currículo escolar vigente, desde o $6^{\circ}$ ano, questões relativas ao Sol, à Terra e à Lua já deveriam, paulatinamente, ser trabalhadas, a fim de que no $8^{\circ}$ ano os fenômenos de nossa investigação pudessem ser abordados detalhadamente pelo professor em suas aulas.

Todavia, as dificuldades que os estudantes apresentaram tanto para fornecer explicações sobre as fases da Lua e os Eclipses, como na construção de relações espaciais, nos indica que as práticas escolares sobre o tema têm sido insuficientes para que concepções menos aparentes e alicerçadas no senso comum possam ser sobrepostas pelas crenças com base na Ciência.

A transposição de uma crença, calcada no senso comum e nas experiências cotidianas, envolve processos complexos de construção de novos conhecimentos que, por sua vez, implicam em acréscimos e reorganizações, por meio de subsistemas que se constroem em velocidades diferentes. Nossa busca cognitiva é sempre por uma estabilidade coerente, pois por meio dela é possível superar os desequilíbrios, a partir de uma elaboração constante de novas estruturas. Essa movimentação cognitiva pode ser favorecida ou ignorada pela escola segundo os métodos de ensino empregados (PIAGET, [1969], 2015).

Nesse sentido, um conceito científico necessita ser colocado em relação aos elementos que já compõem as explicações dos estudantes, de forma a desestabilizá-las. O ensino, da atual forma que ainda se organiza, com raízes na transmissão passiva de conhecimentos, pouco colabora nesse sentido à medida que torna central muito mais a memorização de nomes e conceitos que são apresentados nas avaliações e depois descartados cotidianamente. Piaget ([1969], 2015, p. 36) alerta que essa postura educativa, enraizada na transmissão, não se atém ao fato de que a compreensão dá-se pela "atividade interna e que toda assimilação é uma reestruturação ou uma reinvenção".

Acreditamos, portanto, que além de trabalhar com o conhecimento científico, as aulas de Ciências, especificamente aquelas que se dedicam aos conteúdos de Astronomia na educação básica, também precisam abarcar momentos de aprendizagem relacionados às noções espaciais, englobando situações pedagógicas que contemplem a construção do espaço topológico, euclidiano e projetivo. Um exemplo deste trabalho específico seria a proposição de atividades análogas à própria prova operatória que utilizamos em nossa investigação, com questões de perspectivas e projeções no fenômeno físico da luz e da sombra.

Outras atividades precisam, ainda, estar ligadas a movimentação cognitiva que encaminha à construção de hipóteses. Para tal, propõe-se a observação e registro da Lua e suas diferentes posições, cores e formas ao longo de um mês - solicitando aos estudantes que façam esse registro como observadores em um mesmo ponto e no mesmo horário. Somam-se pesquisas, debates e partilhas de informações; construção de modelos que busquem se aproximar e/ou reproduzir o que ocorre no espaço, tais como caixas de observação das fases da Lua e Eclipses (SARAIVA et al. 2007); cenários e movimentos com o próprio corpo em relação ao seu universo próximo, a outros objetos e ampliações cada vez mais descentradas (MANO, 2017).

Importante salientar que esse tipo de experiência, desenvolvida de maneira mais concreta não é por si só suficiente para a construção do conhecimento, mas à medida que 
se percebe que algumas concepções e características do raciocínio hipotético-dedutivo não estão presentes nas crenças dos alunos, organizar situações didáticas menos abstratas parece ser um caminho importante a se seguir, na intenção de se possibilitar a construção de novas formas. Porém, há que sempre se considerar o caráter não passivo que a assimilação destas experiências possui, mediante a intervenção do outro polo do processo a acomodação - que, necessariamente, provoca uma redução do egocentrismo.

Ações didático-pedagógicas construídas a partir da teoria de Piaget, não corresponderão jamais a um leque de materiais ou experiências prontas, pois a essas experiências vinculam-se processos de desenvolvimento dos estudantes. Dessa maneira, defendemos a necessidade de se auxiliar o estudante na construção de formas mais abstratas de relações espaciais. O avanço dessas noções permite a reorganização de subsistemas que formarão novas totalidades do processo de equilibração; isso, aliado aos processos desencadeados nas interações subjacentes ao conteúdo das fases da Lua e dos Eclipses, pode promover quadros mais favoráveis à construção do conhecimento.

A aprendizagem de um novo conteúdo é uma atividade mental construtiva realizada pelo aluno, na qual são construídas e incorporadas à sua estrutura mental os novos significados e representações, em nosso caso, elementos mais próximos ao entendimento científico das fases da Lua e dos Eclipses. Portanto, temos que o educador deve buscar uma adaptação ativa do educando aos ensinamentos das aulas de Ciências e Astronomia, construindo hipóteses, testando-as, justificando-as, pesquisando e buscando explicações. Não será por meio de um material apostilado, com visualização de fotos ilustrativas, cópias de definições, memorização em provas e aulas expositivas que os alunos avançarão.

\section{Considerações finais}

Esta pesquisa teve por objetivo investigar as ideias de estudantes do $8^{\circ}$ ano do ensino fundamental II, sobre a ocorrência das fases lunares e dos Eclipses. Além disso, partindo da hipótese de que as relações constituídas no plano espacial são necessárias para alicerçar a compreensão desses fenômenos, realizamos a aplicação da situação operatória da projeção de sombras, que avalia a construção de perspectivas e relações espaciais.

Nossos resultados revelaram que os participantes, estudantes do ensino fundamental II, apresentaram pouca familiaridade com as temáticas de investigação na perspectiva científica, o que nos leva a pensar sobre a forma como esses conteúdos vêm sendo trabalhados na educação básica. Por isso, alertamos que a construção do conhecimento deve se desvencilhar da mera transmissão de conteúdos ou do simples cumprimento de conteúdos pré-estabelecidos em um programa, ou material didático, de maneira descontextualizada e sem o protagonismo do educando.

Os resultados da aplicação da prova operatória mostraram que os participantes apresentaram condutas, em sua maioria, condizentes com construções espaciais do tipo topológicas e euclidianas, assim como projetivas iniciais.

Tal fato mostra a importância de os educadores considerarem a necessidade do trabalho em sala de aula, mesmo com sujeitos mais velhos, partir de ações que subsidiem o pensamento dos estudantes e promovam a descentração no que tange às relações espaciais.

Defende-se, portanto, que o trabalho pedagógico escolar precisa considerar não apenas a memorização de informações, mas a construção duradoura de conhecimentos. 
Para isso, conteúdos e forma, ou melhor, construções cognitivas precisam caminhar juntas, sendo indispensáveis para a compreensão dos fenômenos ligados aos astros.

\section{Referências}

BARBOSA, R. A.; SOUZA, A. P. O uso da coleção entomológica no ensino de ciências inspirado na teoria piagetiana. Experiências em Ensino de Ciências, Porto Alegre, v. 13, n. 1, 2018.

BARTELMEBS, R.; MORAES, R. Astronomia nos anos iniciais: possibilidades e reflexões. Revista Espaço Pedagógico, Passo Fundo, v. 19, n. 2, 23 abr. 2012.

BASSOLI, F. Atividades práticas e o ensino-aprendizagem de ciência(s): mitos, tendências e distorções. Ciênc. Educ., Bauru, v. 20, n. 3, p. 579-593, 2014.

BASTOS, S. N. D.; CHAVES, S. N. Sobre currículos e saberes: os discursos que fabricam professores de Biologia. Amazônia - Revista de Educação em Ciências e Matemáticas, Belém, v.14, n. 32, jul.-dez., p.174-185, 2018.

COSTA, J. R. V; GERMANO, A. S. M. A aprendizagem sobre fases da Lua numa disciplina de Astronomia na modalidade a distância. In: Simpósio de nacional de educação em Astronomia, 1., 2011. Anais eletrônicos... Rio de Janeiro, 2011. Disponível em:

<snea2011.vitis.uspnet.usp.br/sites/default/files/SNEA2011_TCO30.pdf>. Acesso em: 20 mai. 2021.

CRESWEL, J. W. Projeto de pesquisa: métodos qualitativo, quantitativo e misto. Tradução de Luciana de Oliveira Rocha. 3 ed. São Paulo: Artmed, 2010.

DARROZ, L. et al. Evolução dos conceitos de Astronomia no decorrer da educação básica. São Carlos, Revista Latino-Americana de Educação em Astronomia- RELEA, n. 17, p. 107-121, 2014.

DARROZ, L.M. As fases da Lua e os acontecimentos terrestres: a crença de diferentes níveis de instrução. Revista Latino-Americana de Educação em Astronomia- RELEA, São Carlos, n. 16, p 73-85, 2013.

EICHELER, M.; PARRAT-DAYAN, S.; FAGUNDES, L. C. Concepções de adolescentes e de adultos sobre a sublimação do iodo. Investigações em Ensino de Ciências, Porto Alegre, v. 13, n. 1, p. 95-126, 2008.

ELIAS, D. C. N.; ARAÚJO, M. S. T.; AMARAL, L. H. Concepções de estudantes de ensino médio sobre conceitos de Astronomia e as possíveis contribuições da articulação de espaços não formais de aprendizagem. REnCiMa, São Paulo, v. 2, n. 1, p. 50-68, 2011.

FAGUNDES, A. J. F. M. Descrição, definição e registro de comportamento. São Paulo: Edicon, 1981.

GONÇALVES, P. C. S.; BRETONES, P. S. Um Panorama de Pesquisas do Campo da Educação Sobre a Lua e suas Fases. Ciência \& Educação, Bauru, v. 26, p. 1-23, 2020.

IACHEL, G.; LANGHI, R.; SCALVI, R. M. F. Concepções alternativas de alunos do ensino médio sobre o fenômeno de formação das fases da Lua. Revista Latino-Americana de Educação em Astronomia - RELEA, São Paulo, n. 5, p. 25-37, jan/dez, 2008. 
LAGO, L. G. Lua: fases e facetas de um conceito. 222 f. Dissertação (Mestrado em Ensino de Ciências) - Faculdade de Educação, Instituto de Física, Instituto de Química e Instituto de Biociências, Universidade de São Paulo, São Paulo, 2013.

LAGO, L. G.; ORTEGA, J. L. N. A.; MATTOS, C.R. A investigação científica-cultural como forma de superar o encapsulamento escolar: uma intervenção com base na teoria da atividade para o caso do ensino das fases da Lua. Investigações em Ensino de Ciências, Porto Alegre, v. 24, n. 1, p. 239-260, 2019

LEITE, C. Formação do professor de ciências em Astronomia: uma proposta com enfoque na espacialidade. 274 f. Dissertação (Mestrado em Educação), Universidade de São Paulo, São Paulo, 2006.

LEITE, C.; HOUSUME, Y. Os professores de Ciências e suas formas de pensar a Astronomia. Revista Latino-Americana de Educação em Astronomia, São Carlos, n. 4, p. 47-68, 2007.

MACHADO. D. I.; SANTOS, C. O entendimento de conceitos de Astronomia por alunos da educação básica: o caso de uma escola pública brasileira. Revista Latino-Americana de Educação em Astronomia- RELEA, São Carlos, n. 11, p. 7-29, 2011.

MANO, A. M. P. Aprendizagem de conteúdos da astronomia em uma perspectiva piagetiana: intervenção pedagógica e desenvolvimento cognitivo. Tese (Doutorado em Educação) - 207 f. Universidade Estadual Paulista "Júlio de Mesquita Filho" - Unesp/Campus de Marília, 2017

MANO, A. M. P.; SARAVALI, E. G. As relações entre compreensão das fases lunares e construção de perspectivas: um estudo piagetiano. Braz. Ap. Sci. Rev., Curitiba, v. 3, n. 1, p. 349-369, jan./fev., 2019.

MORAES, C. J. C. A apropriação da teoria de Jean Piaget no ensino de Ciências. 114 f.

Dissertação (Mestrado em Educação), Universidade Federal de Goiás, Goiânia, 2017.

NARDI, R.; CARVALHO, A.M.P. Um estudo sobre a evolução das noções de estudantes sobre o espaço, forma e força gravitacional do planeta Terra. Investigações em Ensino de Ciências, Porto Alegre, n. 1, v. 2, p. 20-39, 1996.

PELLENZ, D. Astronomia no ensino de Ciências: uma proposta potencialmente significativa. 130 f. Dissertação (Mestrado em ensino de ciências e matemática) - Universidade de Caxias do Sul, Caxias do Sul, 2015.

PIAGET, J. A representação do mundo na criança: com o concurso de onze colaboradores. Tradução Adail Ubirajada Sobral e colaboração de Maria Stela Gonçalves. Aparecida: Ideias \& Letras, [1926], 2005.

PIAGET, J. A construção do real na criança. 2 ed. Tradução Álvaro Cabral. Rio de Janeiro: Zahar, [1937], 1975.

PIAGET, J. Biologia e conhecimento. 4 ed. Tradução Francisco M. Guimarães. Petrópolis: Vozes, [1967], 2003.

PIAGET, J. Psicologia e Pedagogia. 10 ed. Tradução Dirceu Accioly Lindoso e Rosa Maria Ribeiro da Silva. Rio de Janeiro: Forense Universitária, [1969], 2015.

PIAGET, J. Epistemologia genética. 3 ed. Tradução Álvaro Cabral. São Paulo: Martins Fontes, [1970], 2007. 
PIAGET, J. Para onde vai a educação? Tradução Ivette Braga. 5 ed. Rio de Janeiro: José Olympio editora, [1972], 1977.

PIAGET, J. A equilibração das estruturas cognitivas. Tradução Marion Merlone dos Santos Penna, Rio de Janeiro: Zahar, [1975], 1976.

PIAGET, J. As formas elementares da dialética. Tradução Fernanda Luiz. São Paulo: Casa do Psicólogo, [1980], 1996.

PIAGET, J.; INHELDER, B. A representação do espaço na criança. Tradução Bernardina Machado de Albuquerque. Porto Alegre: Artes médicas, [1948], 1993.

PUZZO, D. Um estudo das concepções alternativas presentes em professores de Ciências de $5^{a}$ série do ensino fundamental sobre fases da Lua e Eclipses. 122 f. Dissertação (Mestrado em Ensino de Ciências e Educação Matemática) - Universidade Estadual de Londrina, Londrina, 2005.

SARAIVA, M. F. et al. As fases da Lua numa caixa de papelão. Revista Latino-Americana de Educação em Astronomia - RELEA, São Paulo, v. 4, p. 9-26, 2007.

TRUNDLE, K. C.; ATWOOD, R. K.; CHRISTOPHER, J. E. Preservice elementary teachers' conceptions of moon phases before and after instruction. Journal of research in Science teaching, v. 39, n. 7, set., 2002.

ZAIA, L. L. Estruturas operatórias concretas: os agrupamentos. In: Mantovani de Assis, O. Z. (Org). PROEPRE - Fundamentos teóricos para o ensino fundamental. 3 ed. Juiz de Fora: Fábrica de livros, 2015. p. 161-170. 